\title{
Communication \\ Preliminary Research Concerning the Enrichment of Industrial Hemp Extract Residues via Solid State Fermentation with Pleurotus ostreatus
}

\author{
Christos Eliopoulos ${ }^{1,2}$ (D) Giorgos Markou ${ }^{1}$ (D), Nikos Chorianopoulos ${ }^{1}$ (D), Serkos A. Haroutounian ${ }^{2}$ (D) \\ and Dimitrios Arapoglou 1,*(D)
}

1 Institute of Technology of Agricultural Products, HAO-DEMETER, Sof. Venizelou 1, 14123 Athens, Greece; chris_eliopoulos@hotmail.com (C.E.); markougior@gmail.com (G.M.); nchorian@nagref.gr (N.C.)

2 Laboratory Nutritional Physiology \& Feeding, Department of Animal Science,

Agricultural University of Athens, Iera Odos 75, 11855 Athens, Greece; sehar@aua.gr

* Correspondence: darapoglou@itap.com.gr; Tel.: +30-(210)-284-5940

check for

updates

Citation: Eliopoulos, C.; Markou, G.; Chorianopoulos, N.; Haroutounian, S.A.; Arapoglou, D. Preliminary Research Concerning the Enrichment of Industrial Hemp Extract Residues via Solid State Fermentation with Pleurotus ostreatus. Appl. Sci. 2022, 12, 2376. https://doi.org/10.3390/ app12052376

Academic Editor: Antonio Valero

Received: 18 January 2022

Accepted: 23 February 2022

Published: 24 February 2022

Publisher's Note: MDPI stays neutral with regard to jurisdictional claims in published maps and institutional affiliations.

Copyright: (C) 2022 by the authors. Licensee MDPI, Basel, Switzerland. This article is an open access article distributed under the terms and conditions of the Creative Commons Attribution (CC BY) license (https:/ / creativecommons.org/licenses/by/ $4.0 /)$.

\begin{abstract}
The main objective of this study concerns the bioconversion of industrial hemp extract residues (IHER) by applying a solid-state fermentation (SSF) bioprocess as a means to upgrade their nutritional composition, targeting their utilization as a proteinaceous animal feed. For this purpose, IHER underwent an SSF procedure initiated by $P$. ostreatus, and the results indicated that crude proteins were increased by $53.05 \%$. Additionally, a similar pattern was observed concerning cellulose content, which was found to be increased by $5.25 \%$, while lignin concentration exceeded a 2-fold increment. Furthermore, IHER afforded an increased $\beta$-glucan content of approximately $32.51 \%$. These results revealed the significant potential of IHER as a supplement in animal diets after nutritional enhancement via SSF. This study contributes to the concept of the circular economy, thus promoting the reuse of agro-industrial wastes such as IHER in order to produce high-added-value products such as proteinaceous animal feed.
\end{abstract}

Keywords: industrial hemp; solid state fermentation; sustainable management; Pleurotus ostreatus; crude protein enrichment; waste valorization

\section{Introduction}

Food and agro-industrial production are processes annually generating large amounts of exploitable by-products. Within the European Union, the sectors of agriculture, fishery, and forestry were recorded as producing 21 million tons of wastes for the year 2016 alone [1]. Over subsequent decades, the projected increase of the world's population is expected to amplify the produced amount of wastes as a consequence of the relative increase of nutritional needs, highlighting the need of finding a solution regarding their proper disposal [2]. It is evident that the inadequate future management of these materials can provoke serious environmental issues, with adverse effects on human and animal health. The European Commission's Circular Economy Action Plan promotes waste depletion and has legislated several strategies to encourage resource efficiency towards a more sustainable world [3]. In this respect, it must be noted that the practice of disposing the wastes in open fields and the burning of waste are not considered as options due to their negative environmental impact, whereas their incorporation in animal feeding programs presents serious limitations connected with low digestibility and various antinutritional factors [4].

According to Directive 2008/98/EC of the European Parliament, all materials characterized as agro-industrial wastes must have the potential to be utilizable directly in other applications while avoiding any other processes. Accordingly, all endeavors concerning their exploitation must obey the environmental standards and laws avoiding any negative impact on the environment and human health. The vast majority of wastes generated 
from agro-industrial activities are characterized by a variability in their composition [5]. In general, they contain high amounts of cellulose, hemicellulose, and lignin, justifying their categorization as lignocellulosic materials. On the other hand, they also contain proteins, lipids, minerals, sugars, and polyphenols [4,6], highlighting them as valuable raw materials that are suitable for use as substrates easily assimilable by various microorganisms. These wastes, because of their rich nutritional content, are suitable for colonization by several microorganisms, including filamentous fungi, through the performance of the solid state fermentation (SSF) process [7]. The latter constitutes the most suitable biotechnology process for the conversion of these materials into high-added-value products [8]. In this respect, intensively cultivated worldwide edible mushrooms such as Pleurotus ostreatus constitute a potent source of specific hydrolytic and oxidative enzymes that are capable of acting as lignocellulosic degradation agents. This ligninolytic enzyme system is applicable for the valorization of various agro-industrial wastes through the production of high-added-value products by an environmentally acceptable method [4]. Mushrooms are also appreciated for their flavor, texture, and rich nutritional composition. They consist of a plethora of bioactive compounds such as $\beta$-glucans, which have a beneficial impact on human and animal health. $\beta$-glucans are the predominant material of plant cell walls in cereals, yeast, fungi, and mushrooms, which are composed of D-glucose units linked by $\beta$-D-glycosidic bonds. Mushrooms' $\beta$-glucans are linked with $b-(1,3)$ and $(1,6)$ linkages. This branching pattern is responsible for their antitumor and immune-stimulating properties $[9,10]$.

Hemp (Cannabis sativa L.) is included among the herbaceous annual plants that belong to the Cannabinaceae family [11]. Industrial hemp constitutes a cheap source of natural fiber and cannabinoids. It is differentiated from marijuana by the tetrahydrocannabinol (THC) content, which is limited to $0.2 \%$ for Europe and $0.3 \%$ for Canada. The hemp plant originated from India and Persia, but its cultivation has spread throughout countries of temperate and tropical climates. Industrial hemp $(\mathrm{IH})$ is an important crop widely used for various purposes, such as the production of food, fiber, and medicines. Regarding its fiber content, it has been harnessed for the production of textiles, papers, ropes, sails, etc. Russia is the predominant hemp fiber producer and generates $33 \%$ of the world's annual hemp fiber production. Additionally, France, Chile, Serbia, Japan, Germany, China, Italy, and Peru are emerging countries that can be considered as important producers because they have the ability to generate large amounts of fibers [12]. IH is widely known and exploited for its bioactive compounds, because is consists of significant amounts of cannabinoids, including cannabidiol (CBD), tetrahydrocannabinol (THC), cannabichromene (CBC), cannabigerol (CBG), and cannabinol (CBN) [13]. Additionally, IH contains flavonoids, alkaloids, phenols, and terpenes [14]. Cannabinoids have been widely used in the pharmaceutical, cosmetics, and food industry, because they have displayed beneficial properties, (antineurodegenerative, antiemetic, analgesic agent, anti-inflammatory, and antibacterial); hence, isolation of the latter compounds is very important [15]. The most common extraction method is achieved by performing solvent extraction with organic solvents (methanol, ethanol, butane, chloroform, and n-hexane) followed by ultrasound-assisted extraction (UAE), microwave-assisted extraction (MAE), pressurized liquid extraction (PLE), cold pressing, and supercritical fluid extraction (SFE) [15]. The extraction process generates residues with low nutritional and economic value, the majority of which are considered as suitable for use as foodstuffs that will be incorporated into animal diets (ruminants and especially cattle). However, we should remember to provide SSF treatment before application in order to overcome their inhibitory and antinutritional factors [16].

The main aim of the present study concerns the preliminary research of IHERs' treatment by applying the SSF process. The SSF procedure contributes to the upgrade of IHERs' nutritional composition in order for it to become suitable for utilization as a proteinaceous supplement in animal feed. In this respect, this study focuses on the increase of IHERs' protein and $\beta$-glucan content in order to determine their potential for utilization as a novel proteinaceous supplement in animal feed of high nutritional content and value. 


\section{Materials and Methods}

\subsection{Materials and Microorganisms}

The IHER (Naturalence Lab, Athens, Greece), which was used as a substrate for the growth of P. ostreatus, was the solid residue derived after the ethanol extraction process of tetrahydrocannabinol. The moisture content of the IHERs' initial sample that was provided to our Laboratory was $20 \%$. For the accomplishment of the required moisture content, which is considered as essential for SSF's successful implementation and P. ostreatus' development, the initial IHER sample was hydrated by adding and renewing tap water daily to all the examined substrates for three days. After the hydration step, the achieved moisture content was $65.47 \%$, which was close to the optimum value for P. ostreatus. The fermentation procedure was performed in closed glass test vessels of $750 \mathrm{~mL}$ volume. More specifically, $200 \mathrm{~g}$ of each hydrated substrate was placed into the test vessels and was then sterilized by heating at $121^{\circ} \mathrm{C}$ for $15 \mathrm{~min}$. A commercial commodity of the P. ostreatus strain in solid form, “White 2000 P67 LOTTO 1551 MN 01827" (Fungi SEM, La Rioja, Spain) was used as an inoculum. The fungi P. ostreatus in the inoculum had colonized barley seeds and was stored at $4{ }^{\circ} \mathrm{C}$ throughout the experiment.

\subsection{Inoculation and Solid-State Fermentation}

Inoculation was performed in a vertical laminar flow chamber. Inoculum of the P. ostreatus strain was added in a proportion of $5 \% w / w$ on the surface of each substrate. Incubation was carried out in a bioclimatic chamber with a stable temperature of $25^{\circ} \mathrm{C}$ in the absence of light. The total incubation time was 11 days. Each sample was prepared and examined in triplicate.

\subsection{Analytical Methods}

The examined substrates were freeze dried because this process maintains their nutritional and enzyme content. Subsequently, representative samples were taken for the evaluation of the physicochemical parameters (crude proteins, TSS, RSS), fibers (crude fiber substances, cellulose, lignin, and ashes), and $\beta$ glucan content. Moisture and ashes were assessed according to the AOAC methods [17]. Crude protein determination was performed according to the Kjeldahl method, which is considered as AOAC's official method for total nitrogen evaluation [17]. The protein content of the examined substrate was estimated by multiplying the determined nitrogen content (Kjeldahl method) by a factor of 6.25. Total soluble sugars (TSS) were estimated by the phenol-sulfuric acid method of Dubois et al. [18], and reducing soluble sugars (RSS) were estimated by the 3,5-dinitrosalicylic acid (DNS) method of Miller [19]. Sugar evaluations were performed on the aqueous extracts of the samples. Crude fiber substance (CFS) presence was determined in accordance with the Weende method (AOAC Official method 978.10) [17]. Cellulose and lignin content were determined according to the acid-detergent fiber (ADF) method (AOAC Official Method 973.18) [17]. Finally, $\beta$-glucans were assessed using the Megazyme enzymatic assay kit ( $\beta$-Glucan Assay Kit Yeast \& Mushroom, Megazyme Product code: K-YBGL, Bray, Ireland). More specifically, for the determination of total glucan content, ice cold $12 \mathrm{M} \mathrm{H}_{2} \mathrm{SO}_{4}$ was used for the solubilization of 1,3:1,6- $\beta$-D-glucans, $1,3-\beta$-D-glucans, and $\alpha$-glucans and were then hydrolyzed to near completion in $2 \mathrm{M} \mathrm{H}_{2} \mathrm{SO}_{4}$. The remaining fragments of glucan were quantitatively hydrolyzed to glucose using exo-1,3 $\beta$ glucanase and $\beta$-glucosidase; $\alpha$-glucan and sucrose were hydrolyzed to D-glucose and D-fructose, respectively, with glucose's determination being achieved with amyloglucosidase and invertase using GOPOD reagent. $\beta$-glucan content evaluation is determined by the difference between the total glucan content minus the $\alpha$-glucan content. The results of the aforementioned analyzes are expressed as $\mathrm{g} / 100 \mathrm{~g}$ of dry weight.

\subsection{Statistical Analysis}

All analyses were performed in triplicate, and the respective results were expressed as mean \pm standard deviation $( \pm S D)$. Data normality was assessed using the Kolmogorov- 
Smirnov and Shapiro-Wilk tests using Statistica (TIBCO Data Science, TIBCO Software Limited, Dublin, Ireland). The differences between the groups were analyzed by paired $t$-test ( $p \leq 0.05$ was considered significant).

\section{Results}

Figure 1 depicts the mycelium growth at the beginning (Day 0) and at the end (Day11) of fermentation. Table 1 illustrates the results of the assessment of IHERs' moisture and crude protein content as well as TSS and RSS concentration.

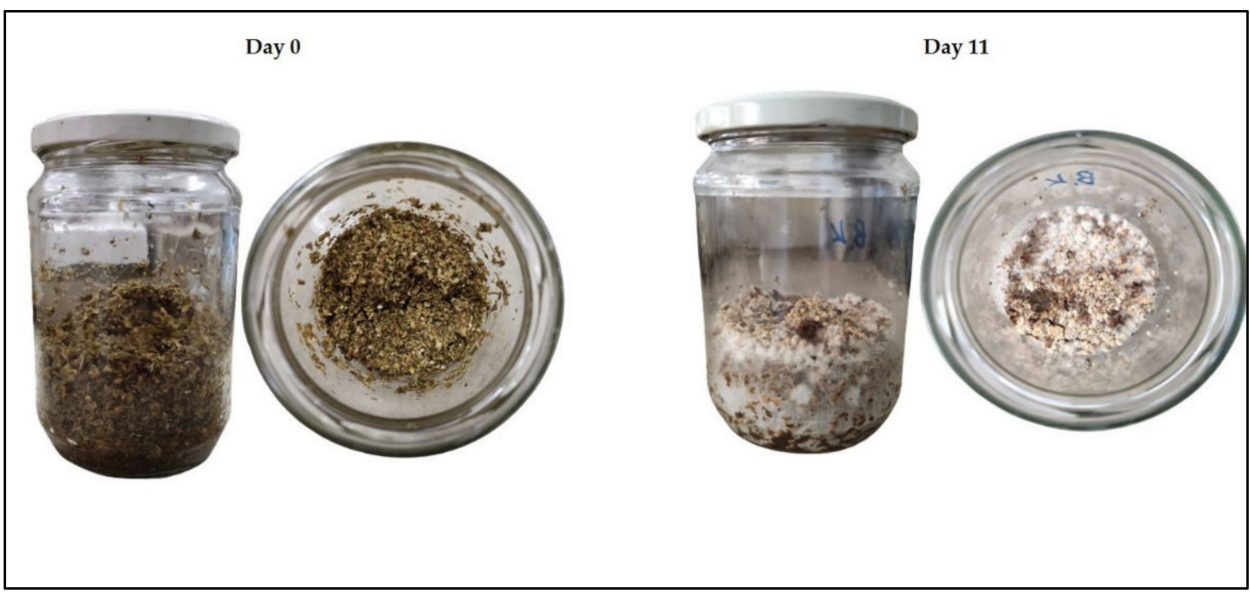

Figure 1. Representative image of mycelial growth at the beginning (Day 0) and at the end (Day 11) of fermentation.

Table 1. Impact of fermentation time on physicochemical composition in the examined substrates.

\begin{tabular}{ccc}
\hline $\begin{array}{c}\text { Parameters } \\
(\mathbf{g} / \mathbf{1 0 0} \mathbf{g})\end{array}$ & Day $\mathbf{0}$ & Day 11 \\
\hline Moisture & $65.47 \pm 0.79^{\mathrm{a} 1}$ & $85.91 \pm 1.19^{\mathrm{a} 2}$ \\
TSS & $3.65 \pm 0.29$ & $2.84 \pm 0.16$ \\
RSS & $3.54 \pm 0.08^{\mathrm{b} 1}$ & $1.36 \pm 0.25^{\mathrm{b} 2}$ \\
Crude Proteins & $15.89 \pm 0.03^{\mathrm{c} 1}$ & $24.32 \pm 0.33^{\mathrm{c} 2}$ \\
\hline
\end{tabular}

TSS, total soluble sugars; RSS, reducing soluble sugars. Statistical analysis was performed between Day 0 and Day 11. Different superscripts between the same letters indicate statistical significance, $p \leq 0.05$.

As shown in Table 1, the moisture content recorded a statistically significant increase $(p \leq 0.05)$ ranging from $65.47 \%$ to $85.91 \%$ between Days 0 and 11 . The concentration of TSS was decreased by $22.19 \%$ without significance $(p \leq 0.05)$, whereas RSS content followed a similar decrease pattern of $61.58 \%$, which was statistically significant $(p \leq 0.05)$ between Days 0 and 11. The crude protein content was increased for the examined substrates, displaying a statistically significant increase $(p \leq 0.05)$ of $53.05 \%$ between Days 0 and 11 of the fermentation period.

Table 2 shows the results concerning CFS, cellulose, lignin, and ash presence in the examined substrates at Day 0 and Day 11. Specifically, the CFS concentration ranged from $12.10 \%$ to $11.14 \%$ during the fermentation process, while the presence of cellulose remained practically unaffected, although a slight increase of 5.25\% was observed. On the other hand, the determined lignin content afforded a statistically significant increase $(p \leq 0.05)$, exceeding 2-fold between Days 0 and 11. Finally, the amount of ash content recorded a statistically significant increase $(p \leq 0.05)$ ranging from $3.14 \%$ to $8.80 \%$ between Days 0 and 11 of fermentation. 
Table 2. Impact of fermentation time on fiber substance content in the examined substrates.

\begin{tabular}{ccc}
\hline $\begin{array}{c}\text { Parameters } \\
(\mathbf{g} / \mathbf{1 0 0} \mathbf{g})\end{array}$ & Day 0 & Day 11 \\
\hline CFS & $12.10 \pm 0.09$ & $11.14 \pm 0.63$ \\
Cellulose & $14.27 \pm 0.44$ & $15.02 \pm 0.28$ \\
Lignin & $6.39 \pm 0.28^{\mathrm{a} 1}$ & $14.26 \pm 0.61^{\mathrm{a} 2}$ \\
Ash & $3.14 \pm 0.06^{\mathrm{b} 1}$ & $8.80 \pm 0.17^{\mathrm{b} 2}$ \\
\hline
\end{tabular}

CFS, crude fiber substances. Statistical analysis was performed between Day 0 and Day 11. Different superscripts between the same letters indicate statistical significance, $p \leq 0.05$.

Figure 2 illustrates the 1,3-1,6 $\beta$-glucan concentration of IHER on Days 0 and 11. In particular, $\beta$-glucans' presence presented a statistically significant increase $(p \leq 0.05)$ by $32.51 \%$ during the fermentation process (Days 0 to 11 ).

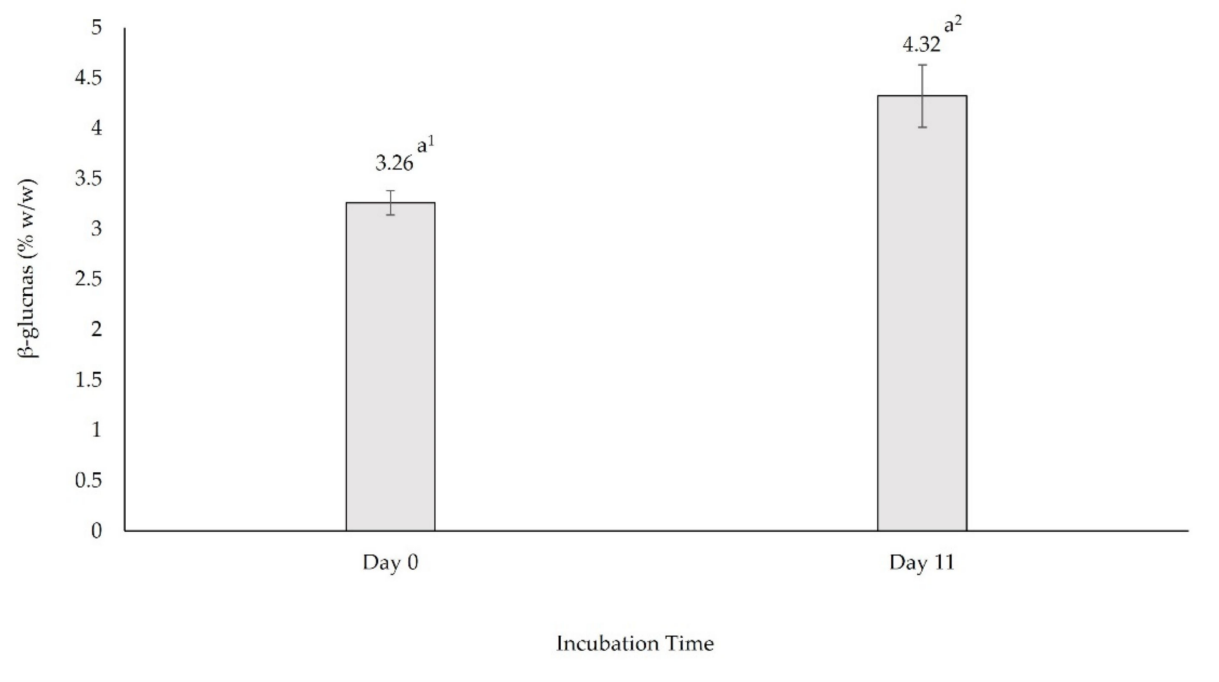

Figure 2. Evaluation of $\beta$-glucan content between Day 0 and Day 11. Different superscripts between the same letters indicate statistical significance, $p \leq 0.05$.

\section{Discussion}

The main objective of this study was the exploitation of IHER as a substrate for the performance of the SSF process initiated by Pleurotus ostreatus in order to evaluate the fermentation outcome as a proteinaceous used in animal feed.

Because moisture constitutes a critical parameter for the successful implementation of SSF, the presence of high moisture content secures the ability of sufficiently supporting fungal growth and nutrient transfer. On the other hand, high moisture levels can cause adverse effects because the particles of the substrates are being covered by a thick water layer, which reduces the distance between the particles, thus limiting air diffusion. In addition, the presence of high moisture levels promotes contamination risk because the substrates facilitate the development of unfavorable microorganisms [20]. When the moisture level is lower than that required, the nutrients' solubility is hindered, resulting in their inadequate uptake by the fungi $[20,21]$. Regarding the closed SSF system, Yoon et al. [20] stated that a sufficient moisture content is closely connected with the substrate's lignocellulosic structure, whereas Abdullah et. al. [22] reported that moisture content can be influenced by the properties of the substrate, such as porosity and particle size. Nagel et al. [23] reported that SSF's water balance can be affected by the required water content for starch hydrolysis, the metabolic water production, the intracellular water uptake thorough biomass production, and finally by the water's evaporation as an effect of the metabolic heat production. These 
four significant factors could possibly explain the moisture content increase during the fermentation procedure. In the present work, our findings concerning moisture are in line with previous literature reports. More specifically, the moisture content at the baseline of fermentation (Day 0) was found to be $65.47 \%$. Although moisture content was not considered as optimum, SSF was successfully performed, with the latter exceeding a proportion of $80 \%$ at the end of the procedure (Day 11). This increment can be rationalized by the lignocellulosic structure of the examined substrates.

The crude protein content of the substrates constitutes the most important variable examined, because it is closely connected with their conversion efficiency into high-added nutritional protein materials. After the end of the SSF process initiated by P. ostreatus, the crude protein content was increased. This observation can be rationalized considering the report of Darwish et al. [24], who stated that such an increment could be resulted by a possible fungal biomass accumulation. According to Akinfemi et al. [25], a possible explanation for the observed increase of crude proteins could be connected with the potential to uptake excess nitrogen via aerobic fermentation. On the other hand, according to Oseni and Akindahunsi [26], the increased crude protein content could be attributed to the secretion of specific proteinaceous extracellular enzymes, which are capable of degrading the materials during the fermentation process. Finally, Fanchini, Terrasan, and Carmona [27] reported that an augmented crude protein concentration may be due to the colonization and growth of the microbial biomass in the substrate. Our results also agree with these literature findings, because the crude protein content was increased for all substrates examined.

The degradation of the lignocellulosic materials is considered as a complex procedure. Specifically, cellulose and hemicellulose modifications are attributed to the action of the hydrolytic enzymes, whereas lignin's degradation is associated with the activity of the oxidative enzymes [4]. White rot fungi such as P. ostreatus secrete extracellular lignin modifying enzymes, of which laccase, lignin peroxidase, and manganese peroxidases are considered as the most efficient. CFS reduction could be caused by the action of the cellulase enzymes that are excreted by the cellulolytic fungi [25]. Additionally, their valorization and transformation by fermentation microorganisms could potentially be one more reason for their depletion, because CFS form an energy source for their biological and other cellular activities [26]. Our results are in line with the reported literature findings because, in our case, the amounts of CFS were determined as slightly decreased at the end of the fermentation.

As we have already highlighted, the degradation of cellulose and hemicellulose is performed through the secretion of hydrolytic enzymes, whereas the action of oxidative enzymes are more effective for lignin modification. Herein, P. ostreatus has the efficacy to degrade lignin and hemicellulose rather than cellulose, and consequently can be characterized as a selective degrader [4]. Thus, in our study, the cellulose content remained practically unaffected because only a slight increase was observed, while lignin presence displayed an increment exceeding 2-fold. This finding can be interpreted in respect of the variation of digestion rate for the examined substrates and its ability to provide the microorganism with the necessary nutrients, namely $\mathrm{N}, \mathrm{P}$, and $\mathrm{K}$, that result in a more extensive degradation [28]. Additionally, fungus has the ability to produce new organic compounds such as $\beta$-glucans and vitamins, enriching the substrate's biomass. In respect of the observed increased lignin content, a possible explanation may be associated with the reduction of hemicellulose level [27].

Ash content was notably increased at the end of the process, presumably as a result of the contribution of the microorganisms in the fermentation process [26]. Additionally, Rajesh et al. [29] stated that ash's increment could be explained by the reduction in organic matter that is performed during the SSF procedure. It must be noted that ash content is considered as a critical parameter for mineral content evaluation, which could contribute in the sector of animal feeding [30]. 
Finally, in respect of the TSS and RSS contents, a similar pattern was observed because both values were reduced at the end of fermentation (Day 11). This can be rationalized by considering the fact that, during the fermentation process, P. ostreatus produced some specific enzymes in order to degrade the lignocellulosic material efficiently. The observed reduction in TSS content could be a result of microorganism activity, which hydrolyzed starch into glucose and utilized them in order obtain energy and to fulfill some other cellular activities [30]. Additionally, another interpretation could possibly be associated with the lignocellulosic nature of the examined substrate. On the other hand, RSS depletion could be explained by considering that $P$. ostreatus probably consumed the fermentable sugars, which served as an energy source for its growth.

In the present study, $\beta$-glucan content was increased by $32.51 \%$ at the end of the fermentation. This is a result of $P$. ostreatus activity, which is able to enlarge $\beta$-glucan content by utilizing the nutrients of the studied substrates. $\beta$-glucan enhancement is very important, considering their beneficial effects in human and animal health, because they exhibit antitumor and immune-stimulating properties. Additionally, analysis provided a significant positive correlation between crude proteins and $\beta$-glucan content $(\mathrm{r}=0.820 p \leq 0.01)$. This correlation could be a possible indication concerning the variation in $\beta$-glucan content through crude protein content determination. Overall, our study highlighted the significance of the SSF process, which is able to develop a novel and enhanced fermentation outcome as a proteinaceous animal feed, enriched in 1,3-1,6 $\beta$-glucan content.

\section{Conclusions}

The study herein highlighted the importance of exploiting the utilization of novel raw materials such as industrial hemp extract residues for the production of innovative proteinaceous animal feed. The results are indicative of IHERs' capability to be bioconverted into crude protein-enriched products with enhanced nutritional compositions. The achieved upgrade revealed IHERs' potential to serve as a suitable supplement for foodstuffs, because the application of SSF initiated by $P$. ostreatus increased the crude protein content by $53.05 \%$, while the cellulose content was enlarged by $5.25 \%$. Additionally, the lignin increment exceeded 2 -fold, and the $\beta$-glucan content increased significantly by $32.51 \%$. Our results are indicative of IHERs' potential for use in animal nutrition as a supplement rich with bioactive compounds, such as $\beta$-glucans, which are well known for their beneficial effects in animal health and welfare. The presented exploitation of agro-industrial wastes demonstrates a pathway that simultaneously resolves various environmental issues and contributes to the concept of the circular economy.

Author Contributions: Conceptualization, C.E., S.A.H. and D.A.; methodology, C.E., G.M., N.C., S.A.H. and D.A.; formal analysis, C.E. and D.A.; investigation, C.E. and D.A.; writing-original draft preparation, C.E.; writing—review and editing, G.M., N.C., S.A.H. and D.A.; supervision, D.A. All authors have read and agreed to the published version of the manuscript.

Funding: This research has been co-financed by the European Union and Greek national funds through the Operational Program Competitiveness, Entrepreneurship, and Innovation, under the call RESEARCH—CREATE-INNOVATE (Grant Number: T1EDK-04331).

Institutional Review Board Statement: Not applicable.

Informed Consent Statement: Not applicable.

Data Availability Statement: Not applicable.

Conflicts of Interest: The authors declare no conflict of interest.

\section{References}

1. Eurostat. Generation of Waste by Economic Activity; European Statistical Office: Luxembourg, 2016.

2. FAO. The Future of Food and Agriculture-Alternative Pathways to 2050; FAO: Rome, Italy, 2019.

3. European Commission. European Commission-Implementation of the Circular Economy Action Plan; European Comission: Brussels, Belgium, 2019. 
4. Ritota, M.; Manzi, P. Pleurotus Spp. Cultivation on Different Agri-Food By-Products: Example of Biotechnological Application. Sustainability 2019, 11, 5049. [CrossRef]

5. Leite, P.; Sousa, D.; Fernandes, H.; Ferreira, M.; Costa, A.R.; Filipe, D.; Gonçalves, M.; Peres, H.; Belo, I.; Salgado, J.M. Recent Advances in Production of Lignocellulolytic Enzymes by Solid-State Fermentation of Agro-Industrial Wastes. Curr. Opin. Green Sustain. Chem. 2021, 27, 100407. [CrossRef]

6. Ravindran, R.; Hassan, S.S.; Williams, G.A.; Jaiswal, A.K. A Review on Bioconversion of Agro-Industrial Wastes to Industrially Important Enzymes. Bioengineering 2018, 5, 93. [CrossRef]

7. Sadh, P.K.; Duhan, S.; Duhan, J.S. Agro-Industrial Wastes and Their Utilization Using Solid State Fermentation: A Review. Bioresour. Bioprocess. 2018, 5, 1. [CrossRef]

8. Soccol, C.R.; da Costa, E.S.F.; Letti, L.A.J.; Karp, S.G.; Woiciechowski, A.L.; de Souza Vandenberghe, L.P. Recent Developments and Innovations in Solid State Fermentation. Biotechnol. Res. Innov. 2017, 1, 52-71. [CrossRef]

9. Chiozzi, V.; Eliopoulos, C.; Markou, G.; Arapoglou, D.; Agriopoulou, S.; El Enshasy, H.A.; Varzakas, T. Biotechnological Addition of $\beta$-Glucans from Cereals, Mushrooms and Yeasts in Foods and Animal Feed. Processes 2021, 9, 1889. [CrossRef]

10. Zhu, F.; Du, B.; Bian, Z.; Xu, B. Beta-Glucans from Edible and Medicinal Mushrooms: Characteristics, Physicochemical and Biological Activities. J. Food Compos. Anal. 2015, 41, 165-173. [CrossRef]

11. Xu, Y.; Li, J.; Zhao, J.; Wang, W.; Griffin, J.; Li, Y.; Bean, S.; Tilley, M.; Wang, D. Hempseed as a Nutritious and Healthy Human Food or Animal Feed Source: A Review. Int. J. Food Sci. Technol. 2021, 56, 530-543. [CrossRef]

12. Manaia, J.P.; Manaia, A.T.; Rodriges, L. Industrial Hemp Fibers: An Overview. Fibers 2019, 7, 106. [CrossRef]

13. Valizadehderakhshan, M.; Shahbazi, A.; Kazem-Rostami, M.; Todd, M.S.; Bhowmik, A.; Wang, L. Extraction of Cannabinoids from Cannabis sativa L. (Hemp)—Review. Agriculture 2021, 11, 384. [CrossRef]

14. AL Ubeed, H.M.; Bhuyan, D.J.; Alsherbiny, M.A.; Basu, A.; Vuong, Q.V. A Comprehensive Review on the Techniques for Extraction of Bioactive Compounds from Medicinal Cannabis. Molecules 2022, 27, 604. [CrossRef] [PubMed]

15. Fathordoobady, F.; Singh, A.; Kitts, D.D.; Pratap Singh, A. Hemp (Cannabis sativa L.) Extract: Anti-Microbial Properties, Methods of Extraction, and Potential Oral Delivery. Food Rev. Int. 2019, 35, 664-684. [CrossRef]

16. Kleinhenz, M.D.; Magnin, G.; Ensley, S.M.; Griffin, J.J.; Goeser, J.; Lynch, E.; Coetzee, J.F. Nutrient Concentrations, Digestibility, and Cannabinoid Concentrations of Industrial Hemp Plant Components. Appl. Anim. Sci. 2020, 36, 489-494. [CrossRef]

17. AOAC. Official Methods of Analysis, 14th ed.; Association of Official Analytical Chemists: Washington, DC, USA, 1995.

18. Dubois, M.; Gilles, K.; Hamilton, J.; Rebers, P.; Smith, F. A Colorimetric Method for the Determination of Sugars. Nature 1951, 168, 167. [CrossRef] [PubMed]

19. Miller, G.L. Use of Dinitrosalicylic Acid Reagent for Determination of Reducing Sugar. Anal. Chem. 1959, 31, 426-428. [CrossRef]

20. Yoon, L.W.; Ang, T.N.; Ngoh, G.C.; Chua, A.S.M. Fungal Solid-State Fermentation and Various Methods of Enhancement in Cellulase Production. Biomass Bioenergy 2014, 67, 319-338. [CrossRef]

21. Fan, L.; Pandey, A.; Mohan, R.; Soccol, C.R. Use of Various Coffee Industry Residues for the Cultivation of Pleurotus Ostreatus in Solid State Fermentation. Acta Biotechnol. 2000, 20, 41-52. [CrossRef]

22. Abdullah, J.J.; Greetham, D.; Pensupa, N.; Tucker, G.A.; Du, C. Optimizing Cellulase Production from Municipal Solid Waste (MSW) Using Solid State Fermentation (SSF). J. Fundam. Renew. Energy Appl. 2016, 6, 1-10. [CrossRef]

23. Nagel, F.J.; Tramper, J.; Bakker, M.S.; Rinzema, A. Model for On-line Moisture-content Control during Solid-state Fermentation. Biotechnol. Bioeng. 2001, 72, 231-243. [CrossRef]

24. Darwish, G.A.M.A.; Bakr, A.A.; Abdallah, M.M.F. Nutritional Value Upgrading of Maize Stalk by Using Pleurotus Ostreatus and Saccharomyces Cerevisiae in Solid State Fermentation. Ann. Agric. Sci. 2012, 57, 47-51. [CrossRef]

25. Akinfemi; Adu; Doherty Conversion of Sorghum Stover into Animal Feed with White-Rot Fungi: Pleurotus Ostreatus and Pleurotus Pulmonarius. Afr. J. Biotechnol. 2010, 9, 1706-1712. [CrossRef]

26. Oseni, O.; Akindahunsi, A. Some Phytochemical Properties and Effect of Fermentation on the Seed of Jatropha curcas L. Am. J. Food Technol. 2011, 6, 158-165. [CrossRef]

27. Fanchini Terrasan, C.R.; Carmona, E. Solid-State Fermentation of Brewer's Spent Grain for Xylanolytic Enzymes Production by Penicillium Janczewskii and Analyses of the Fermented Substrate. Biosci. J. 2015, 31, 1826-1836. [CrossRef]

28. Anele, U.Y.; Anike, F.N.; Davis-Mitchell, A.; Isikhuemhen, O.S. Solid-State Fermentation with Pleurotus Ostreatus Improves the Nutritive Value of Corn Stover-Kudzu Biomass. Folia Microbiol. 2021, 66, 41-48. [CrossRef] [PubMed]

29. Rajesh, N.; Joseph, I.; Paul Raj, R. Value Addition of Vegetable Wastes by Solid-State Fermentation Using Aspergillus Niger for Use in Aquafeed Industry. Spec. Themat. Sect. Sanit. Landfilling 2010, 30, 2223-2227. [CrossRef] [PubMed]

30. Okpako, C.; Ntui, V.; Osuagwu, A.; Obasi, F. Proximate Composition and Cyanide Content of Cassava Peels Fermented with Aspergillus Niger and Lactobacillus Rhamnosus. J. Food Agric. Environ. 2008, 6, 251. 